\title{
Jump-and-Rest Effect of U.S. Business Cycles*
}

\author{
Máximo Camacho ${ }^{+}$ \\ University of Murcia \\ mcamacho@um.es
}

\author{
Gabriel Perez-Quiros \\ Banco de España \\ gabriel.perez@bde.es
}

\begin{abstract}
One of the most familiar empirical stylized facts about output dynamics in the United States is the positive autocorrelation of output growth. This paper shows that positive autocorrelation can be better captured by shifts between business cycle states rather than by the standard view of autoregressive coefficients. The result is extremely robust to different nonlinear alternative models and applies not only to output but also to the most relevant macroeconomic variables.
\end{abstract}

Keywords: Business Cycles, Output Growth, Time Series.

JEL Classification: E32, C22, E27.

\footnotetext{
* We thank Hugo Rodriguez Mendizabal, the editor, two anonymous referees, and the participants at internal seminar series of the Banco de España, Universidad de Alicante, Universidad Complutense de Madrid, Universidad Autonoma de Madrid and FUNDEAR for helpful comments and suggestions. Maximo Camacho thanks Fundacion BBVA for financial support. Any remaining errors are our own responsibility. The views in this paper are those of the authors and do not represent the views of Bank of Spain or the Eurosystem.

+ Corresponding Author: Universidad de Murcia, Facultad de Economía y Empresa, Departamento de Métodos Cuantitativos para la Economía, 30100, Murcia, Spain. E-mail: $\underline{\text { mcamacho@um.es }}$
} 


\section{Introduction}

One of the few empirical observations about US output growth dynamics that is widely accepted in the literature is their positive and significant autocorrelation. Traditionally, both empirical and theoretical models follow the standard view that autocorrelation in output is well characterized by autoregressive processes. At the level of econometric practice, Nelson and Plosser (1982), Watson (1986), or Campbell and Mankiw (1987) use linear autoregressive models to document the positive autocorrelation of US output growth over short horizons. In addition, several authors extend the linear autoregressive models in order to account for the nonlinear business cycle behavior of output growth. The papers of Hamilton (1989), Teräsvirta (1995), and Potter (1995) are significant examples. From the theoretical point of view, the vast majority of the proposals rely on autoregressive models in order to check whether the propagation mechanisms induced by their models match with the observed autocorrelation. Cogley and Nason (1995) include a comprehensive list of examples.

The purpose of this paper is to provide empirical evidence supportive of an alternative view of aggregate growth dynamics. In contrast to autoregressive time series, we show that output growth is better characterized by a recurrent sequence of shifts between two fixed equilibria of high and low growth means. On some particular dates that correspond with business cycle turning points, output growth shows sharp transitions from one regime to the other. However, within each of these regimes, shocks have no dynamic effect and output growth fluctuates around state-dependent means as a white noise exhibiting no conditional autocorrelation. We find that a model with these simple dynamics is dynamically complete in the sense that further lags of output growth do not matter in order to explain current growth. This finding is in line with the results obtained by Kim, Morley and Piger (2005) and Morley and Piger (2006) in independent works. ${ }^{1}$

In order to show this fact, we begin our analysis in a simple scenario in which we assume that the switches between the two states coincide with the widely accepted record of turning points identified by the National Bureau for Economic Research (NBER). Under this assumption, we obtain that, once the NBER business cycle phases are accounted for, the standard autoregressive parameters are no longer statistically significant and the estimated model is dynamically complete. In addition, we find that the statistical significance of the autoregressive parameters falls more when the regime shifts are those associated with the NBER chronology, as opposed to millions of potential

\footnotetext{
${ }^{1}$ These authors also find that there is no need for autoregressive coefficients in the growth rates once the nonlinearities are correctly specified. However, their models are more complex than ours because their purpose is to show the importance of the "third phase" in the business cycle.
} 
alternative chronologies. This fact provides the NBER sequence with a "unique" feature never previously found in the literature.

In spite of these findings, we appreciate the limitations in terms of availability and endogeneity of using the NBER sequence to model the dynamic specification of output growth. In order to overcome these limitations, we consider nonlinear extensions to the baseline model that provide inference of the business cycle shifts without any of the inconveniences of exogenously considering the location of the NBER turning points. To ensure that our results are independent of any particular nonlinear specification, we use a wide range of nonlinear alternatives that are able to identify sequences of business cycle states which are similar to the NBER chronology. Significantly, the fact that autoregressive coefficients are not explicitly needed once these models have accounted for regime switches is robust to any of them.

To ensure that we are addressing the actual data generating process for output growth appropriately, we carry out several robustness checks. First, we check that the absence of autoregressive parameters once we take into account the business cycle is an intrinsic characteristic of the output growth time series and not a consequence of the particular sample period selected in the paper or the last output growth releases. Second, we obtain that the recurrence of declines and recoveries proposed by the NBER's dating committee is one of the very few sequences of business cycle dummies which reduce the need for autoregressive parameters. Third, while we have primarily focused on output growth, we detect that the absence of autoregressive parameters, after controlling for the business cycle, has been an important secular regularity affecting other key macroeconomic aggregates, such as real consumption, investment, and sales. Finally, we empirically show that simple multiequilibria models in which the shifts among equilibria are governed by Markov chains with no autoregressive parameters may be good starting specifications in order to replicate the main U.S. business cycle characteristics.

This new characterization of output growth (and other economic aggregates) has several important implications. First, our findings can be interpreted as empirical evidence in favor of recent developments in theoretical macroeconomics that explain output dynamics as stochastic switches between periods of low and high growth with different sources of business cycle fluctuations. Examples of these papers are Evans, Honkapohja and Romer (1998), which relies on complementarities among different types of capital goods, and Azariadis and Smith (1998), where adverse selection problems in financing capital goods create credit cycles associated with business cycles. In this context, models with no autoregressive parameters may be useful in paving the way for further studies along these lines. Second, Cogley and Nason (1995) pointed out the difficulties that real-business-cycle (RBC) models have in reproducing the autocorrelation in output growth, and consider this fact a failure of RBC models. We believe our results may justify the resuscitation of some of these theoretical models that have been neglected on 
the basis of autoregressive parameters as the unique source of the output growth short-run persistence. Finally, from a technical point of view, predictions, impulse responses, and dynamic multipliers obtained in nonlinear contexts become much simpler and more intuitive since they solely rely on our beliefs about current and future states of the cycle. In addition, the absence of autoregressive parameters minimizes the mathematical complexity and the computational cost of simulation and calibration exercises.

The paper is organized as follows. Section 2 outlines the standard and new stylized facts about the U.S. economy, providing a simple scenario to take them into account and introducing the main characteristics of the absence of autoregressive parameters. Section 3 examines the robustness of this new fact to the sample period, to the business cycle chronology, and to other real macroeconomic aggregates. Section 4 reveals how the results of the nonlinear specifications, which generate inferences about business cycle timing, corroborate the previous findings. Section 5 evaluates the empirical reliability of our new characterization of output growth. Section 6 concludes.

\section{New facts about output growth dynamics}

\subsection{Stylized facts}

The time series literature reports three stylized facts about postwar output growth dynamics in the United States: output growth is positively autocorrelated, it exhibits a remarkable business cycle dependence, and its volatility declined in the mid-eighties. Quotes referring to these facts can be found throughout the literature, but we can easily appreciate them just by having a look at the time series. Figure 1 presents these facts for the growth rate of U.S. real Gross Domestic Product (GDP) for the period 1953.1-2006.4. In this figure, Chart 1 reports the total and partial sample autocorrelation functions for output growth, along with the ninety-five confidence bands ( $\pm 2 / \sqrt{T}$, where $T$ is the sample size). Chart 2 plots the output growth series, along with several shaded areas that correspond to the NBER recessions, and a vertical dashed line that refers to $1984.1 .^{2}$ Finally, Chart 3 shows the kernel density estimate of output growth before and after the volatility break of 1984.1.

As shown in Chart 1, the pattern of the total sample autocorrelation function appears to be consistent with the simple geometric decay of first order autoregressive processes, henceforth $\mathrm{AR}(1)$. In addition, the partial autocorrelation function could be viewed as dying out after one lag, also consistent with the AR(1) hypothesis with an autoregressive parameter of about 0.32 . This standard result suggests that output growth presents positive

\footnotetext{
${ }^{2}$ This date refers to the structural break in volatility found in Kim and Nelson (1999) and McConnell and Perez-Quiros (2000).
} 
autocorrelation that could be modeled in specifications that incorporate autoregressive parameters. This framework is adopted by Cogley and Nason (1995) to review the standard theoretical real-business-cycle (RBC) models and to incorporate exogenous sources of dynamics in order to replicate these impulse dynamics.

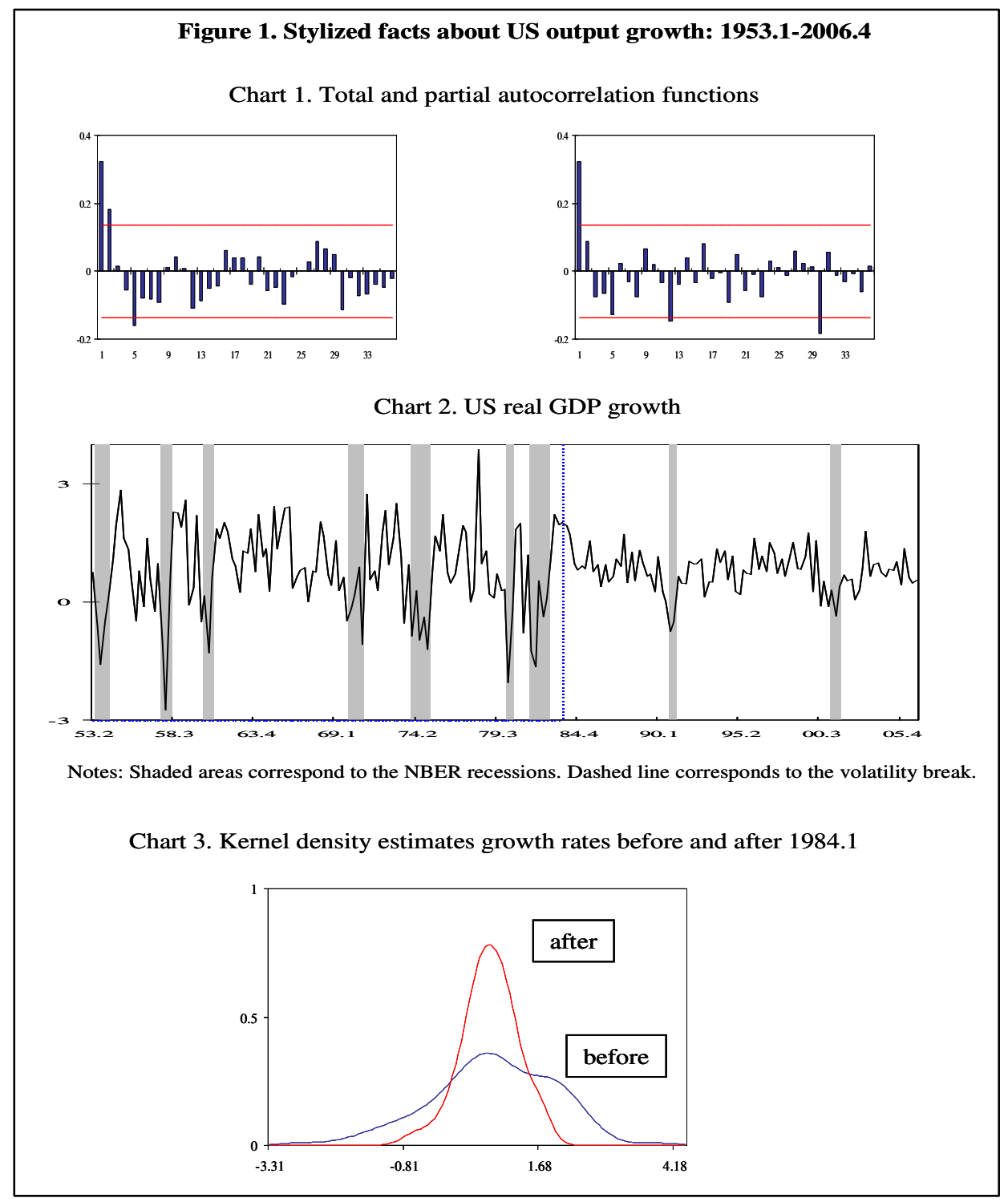

Chart 2 and the first column of Table 1 reveal that, while output growth fluctuates around its mean of 0.80 , the broad changes of direction in the series seem to mark quite well the NBER-referenced business cycles. During expansions, output growth is usually higher (mean of 1.01) than its unconditional mean, but declines significantly within recessions (mean of 0.50). However, these business cycle differences do not seem to affect output 
volatility (standard deviations of 0.73 in expansions and 0.84 in recessions). Simple tests of the null of no different within-recessions and withinexpansions means and variances are clearly rejected for the means and non rejected for the variances ( $p$-values of 0.00 and 0.24 , respectively).

Finally, Kim and Nelson (1999), and McConnell and Perez-Quiros (2000), among other authors, have recently detected a substantial moderation in output growth volatility, with the suggestion that this moderation is well modeled as a single break in the mid-eighties. We show empirical evidence in favor of this fact in the first column of Table 1. In particular, we update the supremum, exponential, and average tests used by McConnell and Perez-Quiros (2000) to corroborate that 1984.1 is still the more appropriate break date to consider the structural change in volatility ( $p$-values of 0.00 ). This fact is also illustrated in Figure 1 (Chart 3) where, after the break, the distribution of output growth is clearly more tightly centered on its mean. The results of the KolmogorovSmirnov test and the Wilconxon tests of equality of the quartiles are also displayed in Table 1, where the null of no change in the distribution of output growth is clearly rejected. However, contrary to the case of the business cycle, this break does not seem to affect the mean but the volatility. The former only moves from 0.81 to 0.77 while the latter falls dramatically from 1.13 to 0.49 . This result is reinforced by the standard tests of no different means and variances that show $p$-values of 0.38 and 0.00 , respectively.

\subsection{A simple approach}

To deal with the previous facts about output growth dynamics, a good place to start is a simple linear autoregressive model. The evidence presented in the previous section supports a first order process as the best initial candidate. The first column of Table 2 presents the estimates of this model, labeled as M1,

$$
y_{t}=a_{0}+a_{1} y_{t-1}+\varepsilon_{t}
$$

where $y_{t}$ represents output growth at time $t$, and $\varepsilon_{t} \sim N(0, \sigma)$, which is identically and independently distributed over time. The estimated autoregressive coefficient is about 0.32 and generates an endogenous propagation of impulses that accounts for the positive autocorrelation stated above. That is to say, the $k$-period ahead impact of an unanticipated shock is estimated to be $0.32^{k}$. Figure 2 (Chart 1) shows the in-sample fitting of this model by plotting both the actual and the estimated growth rates. As expected, after the negative shocks that characterize the peaks, output growth falls during recessions. However, it is interesting to note that, in all recessions, due to the smooth dynamics implicit in this autoregressive model, estimates notably remain above the actual series. 
Table 1. Summary statistics of U.S. macroeconomic series and analysis of the break in volatility

Statistics of US Macroeconomic series

\begin{tabular}{|c|c|c|c|c|c|c|c|c|}
\hline \multirow[b]{3}{*}{$\mathrm{AR}(1)$} & & GDP & PCE & GPDI & GCI & EGS & IGS & FSDP \\
\hline & \multirow{2}{*}{$\begin{array}{l}\text { Coefficient } \\
\text { test }^{(1)}\end{array}$} & 0.32 & 0.28 & 0.15 & 0.16 & -0.27 & -0.04 & 0.27 \\
\hline & & 0.00 & 0.00 & 0.02 & 0.02 & 0.00 & 0.54 & 0.00 \\
\hline \multirow{2}{*}{$\begin{array}{l}\text { AR(1) } \\
\text { NBER }\end{array}$} & \multirow{2}{*}{$\begin{array}{l}\text { Coefficient } \\
\text { test }{ }^{(2)}\end{array}$} & 0.03 & 0.08 & -0.06 & 0.16 & -0.32 & -0.15 & 0.02 \\
\hline & & 0.64 & 0.24 & 0.40 & 0.02 & 0.00 & 0.02 & 0.73 \\
\hline \multirow{7}{*}{ Mean } & Total & 0.80 & 0.87 & 0.99 & 0.49 & 1.49 & 1.53 & 0.79 \\
\hline & Recessions & -0.50 & 0.12 & -4.68 & 0.33 & -0.52 & -1.37 & -0.10 \\
\hline & Expansions & 1.01 & 1.00 & 1.94 & 0.51 & 1.83 & 2.02 & 0.95 \\
\hline & test $^{(3)}$ & 0.00 & 0.00 & 0.00 & 0.22 & 0.00 & 0.00 & 0.00 \\
\hline & Before 1984 & 0.81 & 0.87 & 0.97 & 0.63 & 1.45 & 1.43 & 0.80 \\
\hline & After 1984 & 0.77 & 0.88 & 1.03 & 0.44 & 1.55 & 1.67 & 0.79 \\
\hline & test $^{(3)}$ & 0.38 & 0.44 & 0.46 & 0.14 & 0.43 & 0.32 & 0.48 \\
\hline \multirow{7}{*}{$\begin{array}{l}\text { Standard } \\
\text { deviation }\end{array}$} & Total & 0.92 & 0.69 & 4.58 & 1.16 & 3.89 & 3.51 & 0.74 \\
\hline & Recessions & 0.84 & 0.90 & 4.76 & 1.41 & 4.18 & 3.99 & 0.83 \\
\hline & Expansions & 0.73 & 0.56 & 3.79 & 1.11 & 3.74 & 3.18 & 0.61 \\
\hline & test $^{(4)}$ & 0.24 & 0.00 & 0.07 & 0.15 & 0.36 & 0.07 & 0.06 \\
\hline & Before 1984 & 1.13 & 0.78 & 5.29 & 1.67 & 4.96 & 4.32 & 0.81 \\
\hline & After 1984 & 0.49 & 0.36 & 2.83 & 0.91 & 1.90 & 1.75 & 0.44 \\
\hline & test ${ }^{(4)}$ & 0.00 & 0.00 & 0.00 & 0.00 & 0.00 & 0.00 & 0.00 \\
\hline
\end{tabular}

Break tests:

Analysis of the break in volatility

$\begin{array}{llllllll}\text { Date } & 84.1 & 92.1 & 88.1 & 67.1 & 82.3 & 85.1 & 92.4 \\ \text { Supremum }^{(5)} & 0.00 & 0.00 & 0.09 & 0.14 & 0.02 & 0.01 & 0.07 \\ \text { Exponential }^{(5)} & 0.00 & 0.00 & 0.02 & 0.02 & 0.00 & 0.00 & 0.03 \\ \text { Average }^{(5)} & 0.00 & 0.00 & 0.02 & 0.01 & 0.00 & 0.00 & 0.02\end{array}$

Kolmogorov-Smirnov Test of equal distributions before and after the break:

$\begin{array}{llllllll}\text { Statistic } & 0.25 & 0.21 & 0.17 & 0.26 & 0.22 & 0.25 & 0.17 \\ \text { Critical value } & 0.17 & 0.20 & 0.18 & 0.19 & 0.17 & 0.18 & 0.20\end{array}$

Wilconxon test of equal quartiles before and after the break:

$\begin{array}{lllllllll} & \text { Total } & 0.30 & 0.45 & -1.17 & -0.27 & -0.28 & -0.30 & 0.36 \\ \text { First } & \text { Before break } & 0.16 & 0.41 & -1.87 & -0.63 & -1.66 & -1.11 & 0.26 \\ \text { Quartile } & \text { After break } & 0.50 & 0.62 & -0.93 & -0.11 & 0.59 & 0.75 & 0.46 \\ & \text { test }^{(6)} & 0.00 & 0.00 & 0.00 & 0.00 & 0.00 & 0.00 & 0.00 \\ & & & & & & & & \\ & \text { Total } & 1.30 & 1.31 & 3.73 & 1.18 & 3.25 & 3.32 & 1.24 \\ \text { Third } & \begin{array}{l}\text { Before break } \\ \text { Quartile }\end{array} & 1.68 & 1.41 & 4.25 & 1.96 & 4.08 & 4.18 & 1.30 \\ & \begin{array}{l}\text { After break } \\ \text { test }^{(6)}\end{array} & 1.05 & 1.08 & 2.76 & 1.00 & 2.60 & 2.85 & 1.07 \\ & 0.00 & 0.00 & 0.00 & 0.00 & 0.00 & 0.00 & 0.01\end{array}$

Notes. Real and seasonally adjusted variables in columns are Gross Domestic Product (GDP), Personal Consumption Expenditures (PCE), Gross Private Domestic Investment (GPDI), Government Consumption and Investment (GCI), Exports of Goods and Services (EGS), Imports of Goods and Services (IGS), and Final Sales of Domestic Product (FSDP). Numbers are the $p$-values of the following nulls: (1) slope parameter in an AR(1) is zero (2) slope parameter in an AR(1) and NBER dummy is zero (3) no different means, (4) Bartlett's test of equal standard deviations, (5) no volatility break as described in Margaret McConnell and Gabriel Perez-Quiros (2000), (6) no different quartile. 


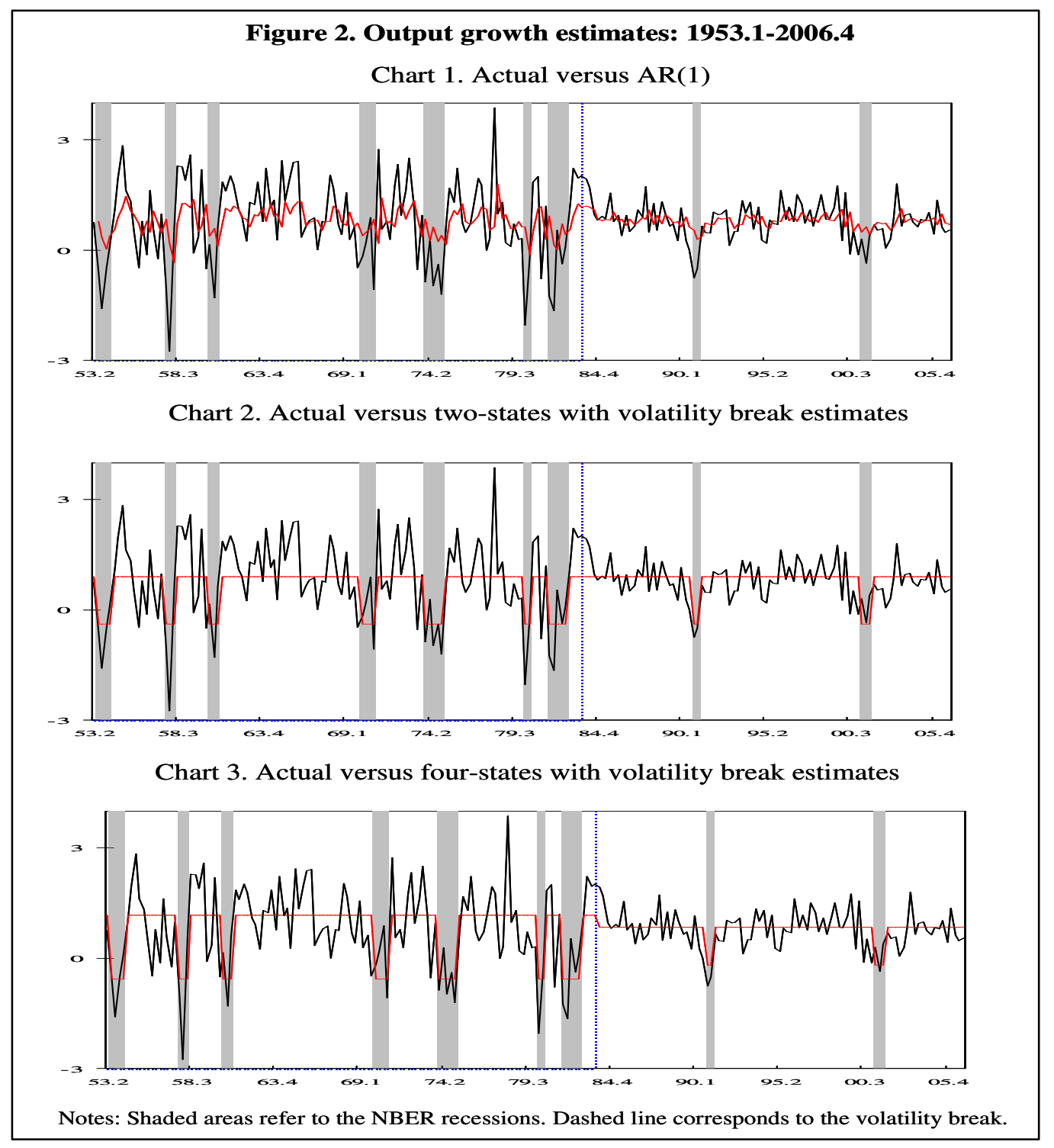

The simple model in M1 can be easily extended to take into account the volatility break simply by assuming that $\varepsilon_{t} \sim N\left(0, \sigma_{t}=d_{0}+d_{1} B_{t}\right)$, where $B_{t}$ is a dummy that equals one in the period 1984.1-2004.1. The second column of Table 2, labeled as M2, presents the estimates of this specification. The estimate of the coefficient $d_{l}$ is negative and statistically significant, showing the reduction in volatility of output growth.

\subsection{Jump-and-rest effect of business cycles}

In this section we look at how business cycle fluctuations influence the positive autocorrelation of output growth documented in the previous section, 
and its relationship to the standard view of autoregressive coefficients. To address this question, the simplest way of taking into account the whole set of stylized facts is by adding a dummy variable to the previous baseline model, $\mathrm{M} 2$, which is equal to one in the NBER recessionary periods.

Table 2. Simple linear time series models of U.S. output growth

\begin{tabular}{|c|c|c|c|c|c|c|}
\hline & M1 & M2 & M3 & M4 & M5 & M6 \\
\hline$a_{0}$ & $\begin{array}{c}0.54 \\
(0.08)\end{array}$ & $\begin{array}{c}0.54 \\
(0.07)\end{array}$ & $\begin{array}{l}0.89 \\
(0.08)\end{array}$ & $\begin{array}{l}0.91 \\
(0.04)\end{array}$ & $\begin{array}{l}0.91 \\
(0.04)\end{array}$ & $\begin{array}{c}1.17 \\
(0.09)\end{array}$ \\
\hline$a_{l}$ & $\begin{array}{c}0.32 \\
(0.06)\end{array}$ & $\begin{array}{c}0.31 \\
(0.06)\end{array}$ & $\begin{array}{c}0.05 \\
(0.07)\end{array}$ & & & \\
\hline$b_{0}$ & & & $\begin{array}{l}-1.30 \\
(0.18)\end{array}$ & $\begin{array}{l}-1.30 \\
(0.14)\end{array}$ & $\begin{array}{l}-1.31 \\
(0.15)\end{array}$ & $\begin{array}{l}-1.73 \\
(0.20)\end{array}$ \\
\hline$c_{0}$ & & & & & & $\begin{array}{l}-0.33 \\
(0.10)\end{array}$ \\
\hline$c_{1}$ & & & & & & $\begin{array}{r}0.70 \\
(0.28)\end{array}$ \\
\hline$d_{0}$ & $\begin{array}{c}0.87 \\
(0.04)\end{array}$ & $\begin{array}{c}1.08 \\
(0.07)\end{array}$ & $\begin{array}{c}0.91 \\
(0.06)\end{array}$ & $\begin{array}{c}0.92 \\
(0.06)\end{array}$ & $\begin{array}{c}0.92 \\
(0.06)\end{array}$ & $\begin{array}{c}0.88 \\
(0.06)\end{array}$ \\
\hline$d_{l}$ & & $\begin{array}{l}-0.59 \\
(0.08)\end{array}$ & $\begin{array}{l}-0.44 \\
(0.08)\end{array}$ & $\begin{array}{l}-0.46 \\
(0.07)\end{array}$ & $\begin{array}{l}-0.46 \\
(0.07)\end{array}$ & $\begin{array}{l}-0.44 \\
(0.07)\end{array}$ \\
\hline$d_{2}$ & & & & & $\begin{array}{l}-0.27 \\
(0.37)\end{array}$ & \\
\hline $\ln L$ & -77.37 & -48.02 & -23.51 & -24.04 & -24.01 & -18.04 \\
\hline
\end{tabular}

Notes. Entries refer to estimates and standard errors (in parenthesis) that correspond to an AR(1) for output growth extended with additive and multiplicative dummies that control for business cycles and volatility break. Last row refers to the log-likelihoods as stated. These models refer to the following expression:

$\mathrm{y}_{\mathrm{t}}=a_{0}+a_{1} y_{t-1}+b_{0} N_{t}+c_{0} B_{t}+c_{1} B_{t} N_{t}+\varepsilon_{t}$, $\varepsilon_{t} \sim N\left(0, \sigma_{t}\right), \quad \sigma_{t}=d_{0}+d_{1} B_{t}+d_{2} N_{t}$.

The dummy $B_{t}$ equals one in the period 1984.1-2006.4, and the dummy $N_{t}$ equals one in the NBER periods of recession.

We use $N_{t}$ to denote the dummy variable that captures the NBER recession periods. There are many different ways in which the break in the volatility dummy $\left(B_{t}\right)$ and the NBER dummy $\left(N_{t}\right)$ can modify the previous regressions. A general characterization of several of these modifications can be summarized by the following expression:

$$
y_{t}=a_{0}+a_{1} y_{t-1}+b_{0} N_{t}+c_{0} B_{t}+c_{1} B_{t} N_{t}+\varepsilon_{t},
$$


where $\varepsilon_{t} \sim N\left(0, \sigma_{t}=d_{0}+d_{1} B_{t}+d_{2} N_{t}\right){ }^{3}$ From this specification, we compute models M3 to M5 which are generalizations of the standard linear autoregressive specification with volatility reduction M2.

In model M3 the NBER dates are allowed to interact with the intercept $\left(b_{0}\right.$ different from 0 ). This extension clearly improves the log likelihood function with respect to M2, which rises from -48.02 to -23.51 . Model M3 already reflects one of the main empirical findings of this paper: once the business cycle movements of output growth have been taken into account, the autoregressive parameter is no longer statistically significant. According to this result, the U.S. economy seems to be characterized by two different steady states. In the first, the average growth rate of output is positive, while in the second it is negative. In each of these states, output growth fluctuates around its mean value as a white noise exhibiting no within-state autocorrelation. The whole-sample autocorrelation of GDP growth is thus accounted for by the serial correlation that characterizes the regime switches of the NBER indicator.

Contrary to the autoregressive processes, in the next period the expected impact of an unanticipated one-unit increase in current output growth is no longer one-third. Instead, the impact depends on the date when the shocks occur. To understand this point, let us take model M4 which, according to the result of the significance test, imposes on M3 the excluding restriction that the autoregressive parameter is zero. Now assume the economy is in the negative growth steady state. For within-recession shocks, the expected impact on output growth is zero, which is expected to remain at its negative growth state mean of -0.39 . However, shocks occurring in the trough have an expected instantaneous impact on output growth of 1.30, and zero in subsequent periods, leading output growth to rise to its positive growth state mean of 0.91. ${ }^{4}$ Figure 2 (Chart 2) illustrates these dynamics: expected output growth switches sharply at turning points and remains constant at each steady state mean until new turning points are reached. This is why we call this particular effect of business cycles on output growth dynamics the jump-and-rest effect of business cycles.

Although formal tests are left to Section 5, the charts in Figure 3 enable useful graphical inspection to investigate the potential serial dependence of model M4 residuals. Chart 1 plots the residuals time series that seem to follow the typical erratic pattern of white noise processes. In addition, Chart 2 shows the total and partial autocorrelation functions of the residuals. They also support the white noise prior since they show that the autocorrelation at any lag is not statistically significant.

\footnotetext{
${ }^{3}$ It is worth noting that we failed to obtain any statistically relevant finding from other variations on the general proposal.

${ }^{4}$ We return to this point in the next section in an attempt to provide inference about turning point identification and a description of the transition between states.
} 


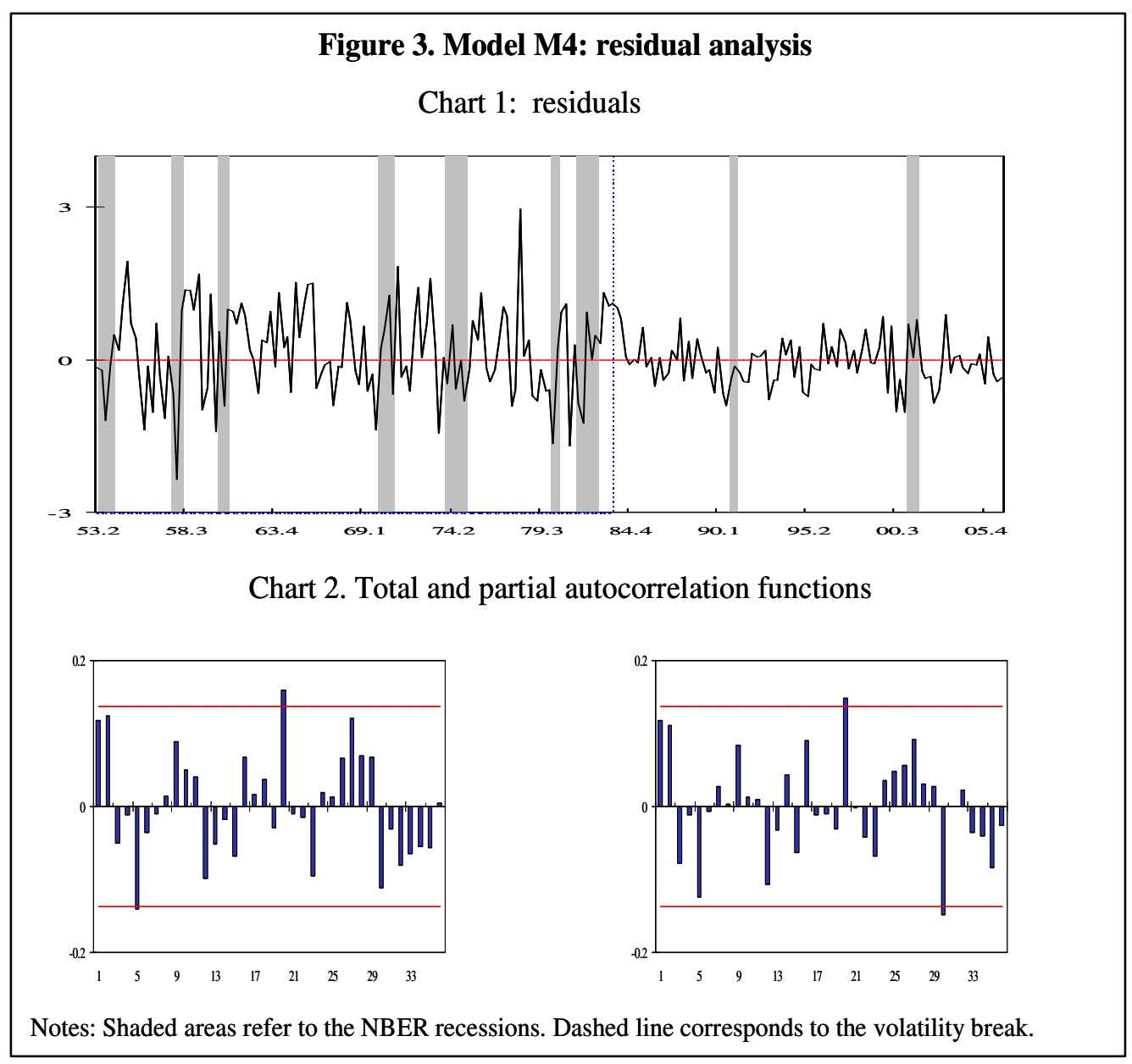

Before concluding this section, we address in Table 2 two additional minor questions about output growth dynamics. The first has to do with the potential business cycle dependence of output volatility. To examine this question, model M5 adds the NBER dummy to the specification of the standard deviation ( $d_{2}$ different from 0$)$. Following the M5 estimates, we conclude that, when the volatility break is accounted for, the recessionary dummy does not affect output volatility (point estimate of -0.27 with standard deviation of 0.37). The second issue deals with the analysis of whether the reduction in volatility induces a narrower gap in the business cycle means. In this respect, model M6 includes the volatility dummy in the mean specification $\left(c_{0}\right.$ and $c_{1}$ different from 0 ). The resulting estimates show that the break significantly affects the business cycle dynamics (the $p$-value of joint significance of these dummies is 0.007). This implies that the volatility reduction may be due to both a narrowing gap between growth rates during recessions and expansions 
as in Kim and Nelson (1999), and a decline in output volatility as in McConnell and Perez-Quiros (2000). ${ }^{5}$

\section{Robustness analysis}

In this section we investigate the robustness of the jump-and-rest effect of business cycles in three different ways. First, we examine whether the absence of autoregressive parameters when accounting for the business cycle dynamics is a recent development or whether it is robust to the sample period considered. Second, we check the extent to which this effect is related to the particular sequence of business cycles proposed by the NBER. Finally, we study whether this effect is limited to output growth or shared by other U.S. major macroeconomic aggregates.

\subsection{Is the jump-and-rest effect robust to the sample period?}

We have detected that, accounting for the business cycle phases, additional autoregressive parameters are no longer statistically significant. However, it would be worth analyzing whether this fact is merely a consequence of the sample period studied or whether it is rather an intrinsic characteristic of the output growth dynamics.

This question is addressed in Figure 4 (first row of charts) by using a recursive approach estimation of output growth. Specifically, we start by estimating the autoregressive parameter for a short sample spanning 1953.1 to 1963.1. Then, we iteratively expand the initial sample by one observation and re-estimate the autoregressive parameter in two different scenarios. In the first, we assume the process to be the simple first-order autoregressive specification stated in (2.1). Chart 1a shows the OLS estimates of the slope parameter and Chart $1 \mathrm{~b}$ plots the $p$-value of the null of non-significativity. In these graphs, we observe a secular decrease in the magnitude of the slope parameter while it constantly remains highly significant. The second scenario modifies the autoregressive process by the inclusion of the additive NBER-recessionary dummy variable $N_{t}$. Chart $1 \mathrm{c}$ shows that, once we allow for business cycle shifts around turning points, the autoregressive parameter becomes negligible, and Chart $1 \mathrm{~d}$ reveals that it has never been statistically significant. These results confirm that, once business cycle shifts have been accounted for, the absence of autoregressive parameters in the output growth specification is robust to the sample period.

\footnotetext{
${ }^{5}$ The output growth mean falls from 1.17 to 0.84 in expansions and rises from -0.56 to -0.19 in recessions after the volatility break. In addition, its standard deviation is reduced from 0.88 to 0.44 .
} 


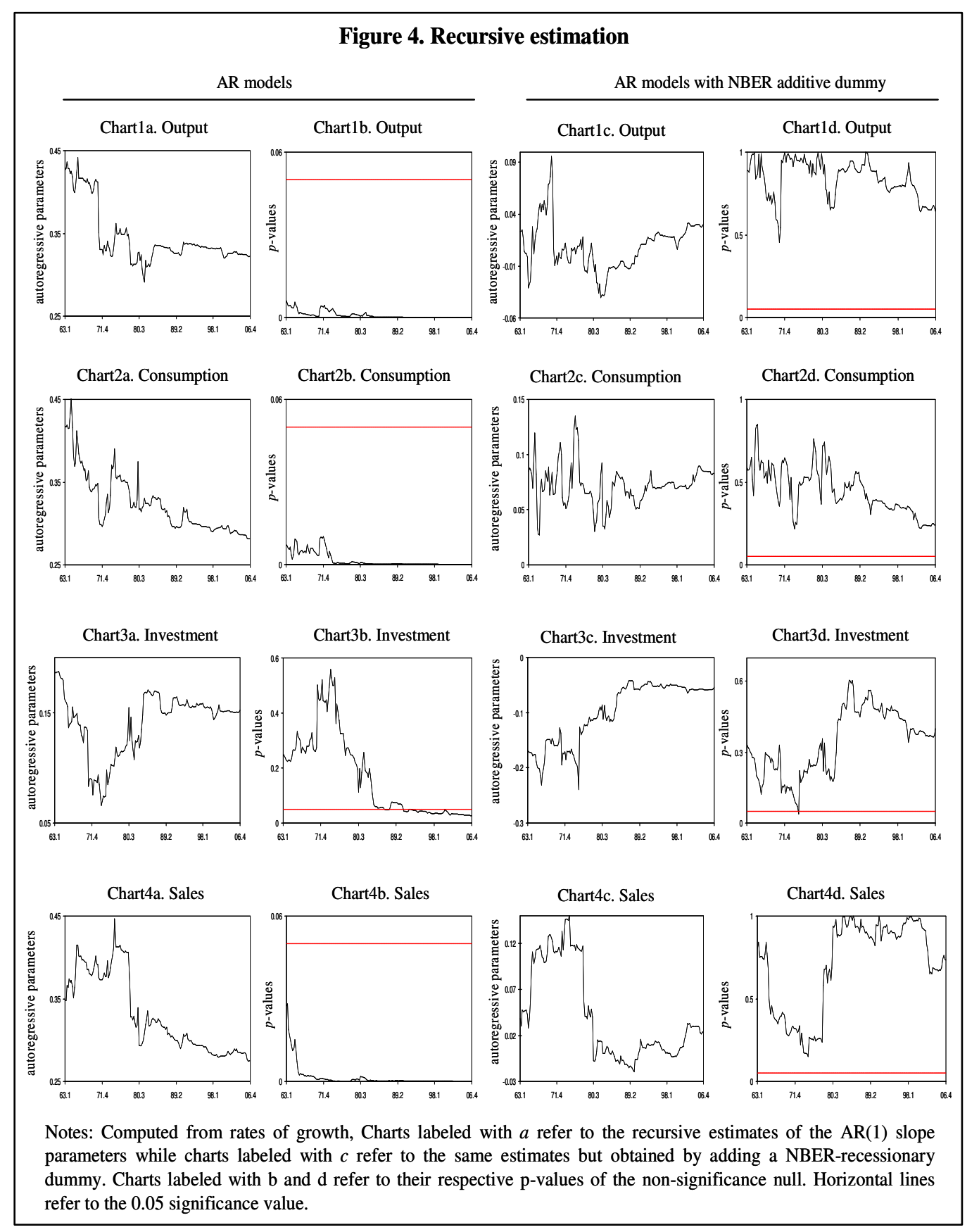

\subsection{On the uniqueness of the NBER cycles}

So far, we have established that the NBER business cycle fluctuations represented by a particular sequence of zeroes (expansions) and ones (recessions) have absorbed and continue to absorb the autocorrelation in output growth dynamics. An obvious question that arises in the development of this property is to examine whether this is common to a few or to many other business cycle sequences, or whether the reduction in the usefulness of autoregressive parameters to model output growth achieved by the NBER chronology converts their sequence in "unique" in some sense.

In order to address this question, we propose different exercises. First, we want to examine to what extent the jump-and-rest effect remains significant 
under minor differences in turning point identifications. To do this, we use leads and lags of the NBER additive dummy as regressors in the OLS regression of GDP growth rates on an intercept and on its lagged value. That is to say, we estimate

$$
y_{t}=\alpha_{i}+\beta_{i} y_{t-1}+\gamma_{i} N B E R_{t-i}+\varepsilon_{t},
$$

for $i=-4, \ldots, 0, \ldots, 4$, where the random error $\varepsilon_{t}$ is iid normal with mean 0 and variance $\sigma^{2}$. In Figure 5, we present the estimated coefficients $\beta_{i}$ for each value of $i$, along with their $95 \%$ confidence intervals. As can be seen, only for $i=0$ does the coefficient $\gamma_{0}$ lead the autoregressive parameter $\beta_{0}$ to be statistically non-significant. All the other values of $i$ other than zero imply confidence intervals that do not contain the value $\beta_{i}=0$. Therefore, minor differences in turning point identification imply the loss of the jump-and-rest effect of business cycles.

Figure 5. Regression with leads and lags of the NBER sequence

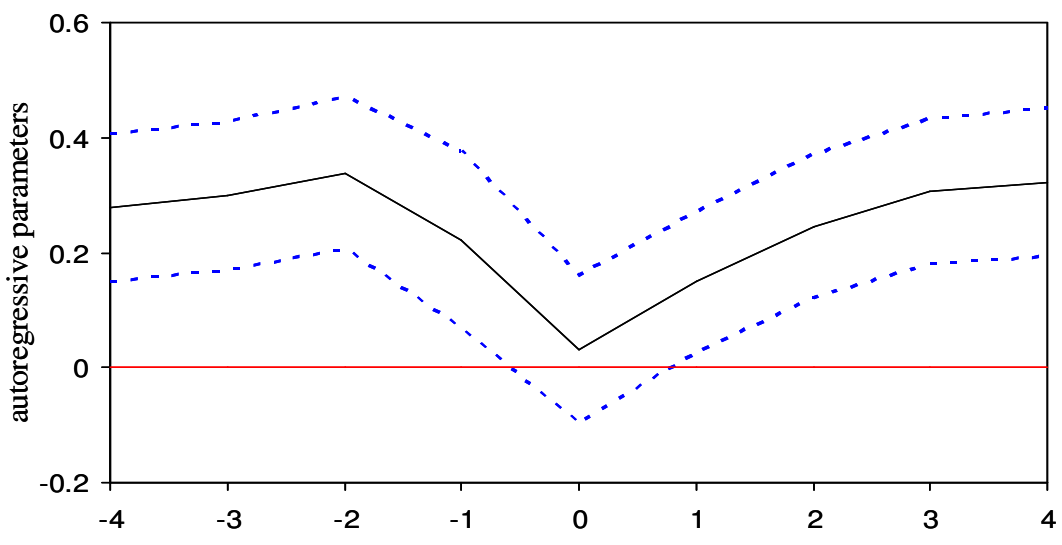

Notes: Dashed lines correspond to $95 \%$ confidence intervals

In a second exercise, we consider how much the absorption of autocorrelation achieved by the NBER chronology is shared by other business cycle sequences. This exercise is performed in two scenarios. In the first, we create business cycle sequences that share the same business cycle properties as the NBER-dated phases. Here, we generate 10,000 blocks of recessions and expansions from a Markov process whose probabilities of staying in expansions, of staying in recessions, and of changing the state give an expected value of the blocks equal to those observed in the NBER data. With these 10,000 series of zeroes and ones, we repeat the regressions outlined in (3.1), where, instead of using NBER leads and lags, we use each of the generated dummies. The result rejects the null hypothesis that the 
autoregressive coefficient is zero in any case. Actually, the minimum value of the t-statistic is 4.13. In the second scenario, we want to avoid the dependence of the analysis with respect to the NBER business cycle characteristics. In this case, we randomly generate 1,000 sets of probabilities of staying in expansions, staying in recessions, and switching the regime. ${ }^{6}$ For each of these vectors of probabilities, we generate 1,000 business cycle dummies and repeat the previous regression exercise. Remarkably, our result is qualitatively the same: of the 1,000,000 regressions (i.e., 1,000 vectors of probabilities times 1,000 dummies) the minimum $t$-statistic of the null that the first order autoregressive parameter is zero is 3.73 . Thus, these results reinforce the idea that the absorption of autocorrelation is only consistent with some particular business cycle characteristics associated with the sequence proposed by the NBER.

Finally, we would like to go even further and try to evaluate the jump-andrest effect against all the possible combinations of zeroes and ones. However, due to the current capacity of our personal computers, the problem seems to be intractable ( 217 observations imply $2^{217}=2.1 * 10^{65}$ possible combinations). ${ }^{7}$ As an alternative, we propose an algorithm for seeking a global minimal value in the autoregressive significance over a huge amount of competing business cycle dummies, but trying to keep the problem computationally feasible. We start the algorithm by generating the 65,536 different combinations of recessions and expansions for the first 16 observations. ${ }^{8}$ We drop from this set of possible combinations those that do not have a minimum size block of two observations (this leaves 19,856 combinations). As usual, we use the remaining combinations as additive business cycle dummies in the first order autoregressive regression and keep only those $\mathrm{k}$ combinations that provide a $p$ value of the null hypothesis of $\beta_{i}=0$ (with $i=0$ ), which is smaller than or equal to that obtained using the NBER sequence. We consider that those $k$ selected business cycle sequences could be followed by an expansion (add one more zero) or by a recession (add one more one), obtaining $2 k$ business cycle combinations. With these $2 k$ combinations, we repeat the exercise of regressing them as dummies in the first order autoregressive time series.

We then continue with this process until we reach the last observation. From this algorithm we obtain that only one sequence of zeroes and ones reduces the autocorrelation in the GDP data more than any other sequence of dummies consistently for most of the samples considered. This sequence is exactly the same as the NBER recessions dummy, but adding as recession periods the quarters 1990.3, 1991.2 and 2001.1. Therefore the 1991 recession may start

\footnotetext{
${ }^{6}$ In order to obtain business cycle dummies with economic meaning, we impose that the probabilities of staying in each state are greater than one half, and that the probability of staying in expansions is greater than the probability of staying in recessions.

${ }^{7}$ In fact, we were able to develop an algorithm that examines the jump-and-rest effect in any combination of zeroes and ones. However, according to our preliminary results, we would have required more than 1 year of iterations to finish up the calculations.

${ }^{8}$ We tried with different starting sample sizes but they yielded the same results.
} 
one period before and end one period later, and the last recession may end one period later, as already pointed out by Camacho (2004) in an independent study. ${ }^{9}$

Summing up all these results, we find that the NBER recession periods represent a succession of blocks of zeroes and ones with a business cycle property, the jump-and-rest effect of business cycles, that has never been studied in the related literature. Our results support the hypothesis that there is something "special" about the sequence of business cycles established by the NBER since it is very close to being the one that most reduces the need to use autoregressive parameters in the GDP growth time series specification. ${ }^{10}$

\subsection{Does it affect other U.S. macroeconomic aggregates?}

Table 1 (last six columns) analyzes whether the stylized facts that have been previously documented for output growth appear in other U.S. real macroeconomic variables. In particular, the analysis includes the rate of growth of Personal Consumption Expenditures (PCE), Gross Private Domestic Investment (GPDI), Government Consumption and Investment (GCI), Exports of Good and Services (EGS), and Final Sales of Domestic Product (FSDP). The business cycle phases seem to affect the first moment (all the series except GCI) but not the second moment (all the series except PCE). The decline in volatility is significant in all the series, using both Bartlett's tests of equal standard deviations ( $p$-values of 0.00) and structural break tests (vast majority of $p$-values below 0.05). The dates of the breaks are in either the mid-eighties (82.3 for EGS, 84.1 for GDP, 85.1 for IGS, and 88.1 for GDPI) or early nineties (92.1 for PCE and 92.4 for FSDP), with the exception of government expenditures, whose break date occurs in the mid-sixties. In addition, with the exception of consumption, the moderation in volatility is associated with reductions in the conditional variance after a break, not with different volatility in different business cycle phases. Specifically, in the case of consumption, the $p$-value of equal (within recessions and within expansions) standard deviations is 0.00 . In the other macroeconomic variables, their respective $p$-values are always higher than the standard significance level of 0.05 .

As in the case of output, the analysis of the autoregressive parameters is the main interest of this paper. The first four rows of Table 1 show that, apart from output, the jump-and-rest effect of business cycles also applies to the series of consumption, investment and sales. For these series, the slope parameters in simple AR(1) regressions are positive and statistically significant. Their point

\footnotetext{
${ }^{9}$ In the last few samples, the same sequence - but considering the slowdown in 2002.4 and 2003.1 as recessions- dominates temporarily the reduction in autoregressive significance.

${ }^{10}$ According to our results, we consider that this particular property of the NBER cycles might be used as an alternative way of identifying the business cycle phases in other countries. However, this is beyond the scope of this paper and we think that it could be material for further research.
} 
estimates are 0.28, 0.15 and 0.17 , and their $p$-values are 0.00, 0.02, and 0.00, respectively. However, they become negligible and statistically insignificant when the additive NBER dummy is introduced into their respective baseline first order autoregressive processes. Specifically, their point estimates become $0.08,-0.06$, and 0.02 , and their $p$-values increase to $0.24,0.40$, and 0.73 , respectively.

Finally, as documented in Figure 4, this empirical fact seems to be very robust to the sample period considered. The secular reduction of the autoregressive parameters is shared by consumption and sales growth but they are always highly statistically significant. However, once the NBER business cycle phases are accounted for, the magnitudes of these parameters are dramatically reduced and never statistically significant. The case of investment is somehow special because, even though the jump-and-rest effect of business cycles has affected its dynamics since the mid-eighties, the slope parameter in a simple autoregressive regression is not statistically significant for series that end prior to these years.

\section{Nonlinear models of output growth}

Although we have found evidence in favor of the two-states model in contrast to the standard view of autoregressive parameters, the scenario proposed to develop the analysis was too simple and had limited empirical application. In particular, we assumed we would observe the discrete shifts between states directly since we used the dichotomous NBER variable as known at each time period. In real time, the NBER dating committee introduces delays in the reporting of the index of up to two years. Moreover, this model fails to capture the fact that the economies can recover on their own since the way that the economy leaves a regime depends almost entirely on the NBER indicator that has been exogenously defined. Finally, using the NBER indicator as an explanatory variable may lead to potential endogeneity problems since the indicator has been constructed on the basis of knowing the actual value for output growth.

We overcome these two problems by using nonlinear extensions to the baseline model presented in the previous section. These specifications are useful because they provide inference about the probability of business cycle shifts in each period with information available up to that period. Furthermore, they allow us to correct the endogeneity problem that may affect the estimations of the previous section. Finally, we show that the main conclusions of this study are invariant to the wide range of nonlinear specifications that we propose to account for the business cycle dynamics of output growth. 


\subsection{Self-exciting threshold autoregressive (SETAR)}

In the autoregressive model enlarged with the business cycle dummy, the mean growth rate switches between business cycle states through the intercept term according to the NBER official classification. One possible way to endogenize the business cycles is the SETAR model, originally proposed by Tong (1978). ${ }^{11}$ In SETAR models, the regime is assumed to be determined by the value of an observed lagged dependent variable, $y_{t-p}$, relative to a threshold $c$. In particular, based on the previous analysis, we propose the following tworegime SETAR model

$$
y_{t}=a_{0}+b_{0} I\left(y_{t-d}\right)+a_{1} y_{t-1}+\varepsilon_{t},
$$

where $\varepsilon_{t} \sim N\left(0, \sigma_{t}=d_{0}+d_{1} B_{t}\right)$. In these models, $I\left(y_{t-d}\right)$ is an indicator function taking the value of one when $y_{t-d} \geq c$, and zero otherwise. It is worth noting that the shifts between the two states is instantaneous by assumption and marked by the changes in the value of the indicator function from zero to one or vice versa.

Since the SETAR model is piecewise linear, all parameters can be easily estimated by maximum likelihood, provided we know the value of the threshold, $c$. However, since the threshold is unknown, we solve the maximization problem by searching the value of the threshold over the observed values of $y_{t-d}$. Finally, we choose the threshold and the lag of output growth that maximize the corresponding log-likelihood function. ${ }^{12}$

We show the parameter estimates in the first two columns of Table 3. The estimates of the baseline model, which appears in the first column as SETAR1, reveal that the maximum likelihood is achieved for a threshold of 0.16 . Thus, the first regime is reached whenever the last period's output growth is greater than 0.16 and is associated with a large conditional mean. The second regime appears when output growth is smaller than 0.16 and is associated with a low mean. In order to add some light to the identification of the SETAR regimes, Figure 6 (Chart 1) plots the values of the indicator function, along with the NBER recessions. Typically, the indicator function is one (past growth is smaller than 0.16) at the official recessions. This confirms that, even though we have not imposed it a priori, the SETAR model makes the dynamics of business cycles endogenous.

\footnotetext{
${ }^{11}$ For an overview of SETAR models, see Hansen (1999) and the references therein.

${ }^{12}$ Following Hansen (1999), we restrict the maximum value of $d$ to be the maximum lag length in the autoregressive specification, and the thresholds to contain at least $10 \%$ of observations in each regime.
} 
Table 3. SETAR and STAR models of U.S. output growth

\begin{tabular}{lcccc} 
& SETAR1 & SETAR2 & STAR1 & STAR2 \\
\cline { 2 - 5 }$a_{0}$ & 0.68 & 0.86 & 0.29 & 0.21 \\
& $(0.09)$ & $(0.05)$ & $(0.13)$ & $(0.12)$ \\
$b_{0}$ & -0.39 & -0.65 & 0.39 & 0.65 \\
& $(0.18)$ & $(0.13)$ & $(0.17)$ & $(0.13)$ \\
$a_{1}$ & 0.17 & & 0.17 & \\
& $(0.09)$ & & $(0.09)$ & \\
$g$ & & & 1162 & 773 \\
& & & $(41901)$ & $(55938)$ \\
$c$ & 0.16 & 0.16 & 0.17 & 0.17 \\
& & & $(1.04)$ & $(0.23)$ \\
& & & & \\
$d_{0}$ & 1.07 & 1.09 & 1.08 & 1.09 \\
& $(0.07)$ & $(0.07)$ & $(0.07)$ & $(0.07)$ \\
& & & & \\
$d_{l}$ & -0.61 & -0.63 & -0.61 & -0.63 \\
& $(0.07)$ & $(0.08)$ & $(0.08)$ & $(0.08)$ \\
& & & & -48.07 \\
& & & &
\end{tabular}

Notes. Entries refer to estimates and standard errors (in parenthesis) that correspond to SETAR and STAR specifications for output growth for the following expressions:

$y_{t}=a_{0}+b_{0} I\left(y_{t-d}\right)+a_{1} y_{t-1}+\varepsilon_{t}$

$\varepsilon_{t} \sim N\left(0, d_{0}\right)$ if $t<1984.1$, and $\varepsilon_{t} \sim N\left(0, d_{0}+d_{1}\right)$ if $t \geq 1984.1$.

The term $I\left(y_{t-d}\right)$ is an indicator function that takes the value 0 or 1 depending on the values of $y_{t-d}$ and $c$ for the SETAR model and it is the transition function stated in the main text for the STAR model. Last row refers to the log-likelihoods.

Something crucial in respect of this paper is that the autoregressive parameter is statistically insignificant (the $p$-value for this test is about 0.08). This result leads to the model SETAR2, which excludes the autoregressive parameters. This confirms our previous findings that, contrary to the standard analysis of output growth, the time series does not need autoregressive parameters when accounting for business cycles. This result corroborates that the jump-and-rest effect of US business cycles is independent of the potential 
endogeneity induced by considering the business cycle phases as those identified by the NBER.

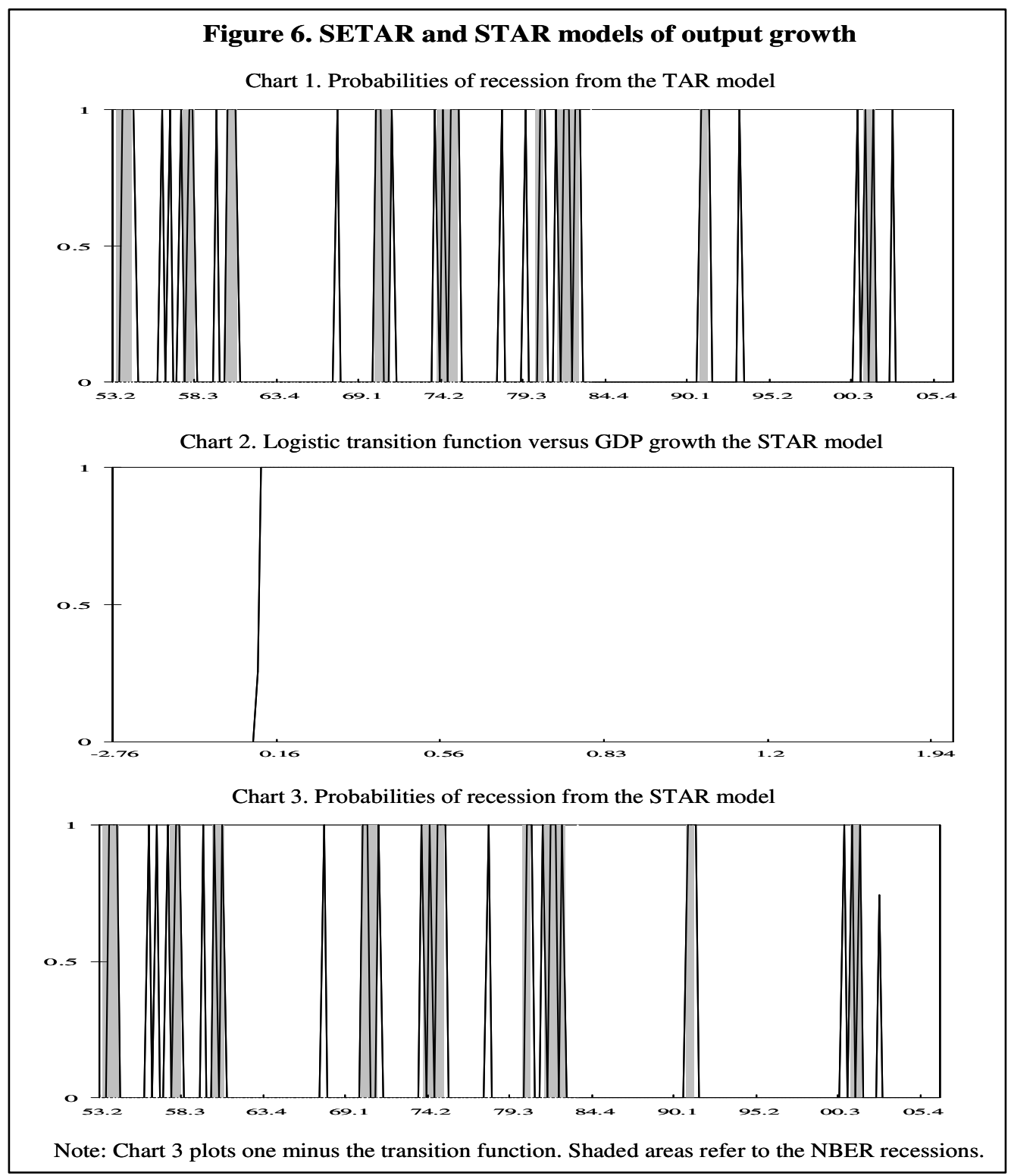

These findings have important implications for analyzing output growth reactions to shocks where, as in the case of the linear model, not only the size of the shock but the date of occurrence matter. Let us assume that output growth at time $t-1$ is, say, equal to 0.20 . Note that this growth is dramatically below the expected value of expansions $(0.86)$ so the economy is potentially close to a peak. However, since the actual growth is still above the threshold, our expected value of output growth at time $t$ is 0.86 since, according to the model, we infer that the economy is still in expansion. However, if a shock of size -0.05 affects the economy in that period $t$, the growth rate would be 0.15 
and that particular shock would send the economy into a recession period in $t+1$ where the expected growth rate is just 0.21 .

\subsection{Smooth transition autoregressive (STAR)}

The hypothesis that U.S. output growth can switch between two states according to the value of an observed lagged variable with respect to a threshold may be generalized by using the STAR models of Teräsvirta (1994). The generalization stems from the fact that these models allow for more gradual transitions between the different regimes by replacing the indicator function in (4.1) with the logistic transition function: ${ }^{13}$

$$
F\left(y_{t-1}\right)=\frac{1}{1+\exp \left[-g\left(y_{t-1}-c\right)\right]} .
$$

The role of the transition function is then to allow the mean growth rate to change monotonically with the values of the transition variable, $y_{t-1}$, with respect to the threshold $c$. The parameter $g$, usually called a smoothing parameter, determines the degree of smoothness of the transition from one regime to the other, in the sense that the higher the parameter the sharper the change (the steeper the slope of the transition function at the threshold).

As in the case of SETAR models, the STAR specification allows us to endow the statistical regimes with economic meaning. In connection to this, the last two columns of Table 3 contain the estimates of the different STAR models that we consider. Also, Figure 6 (Charts 2) shows the estimated transition function. Let us associate the first regime to the values of the lagged growth rate that are sufficiently lower than the threshold to drive the transition function to zero. Hence, from an economic point of view, this regime may be considered as a recession and, according to the parameter estimates, it coincides with periods of relatively low conditional expected growth estimates. As the value of lagged growth increases, the transition function changes monotonically from zero to one. At the limit, for very high lagged growth rates that are obviously associated with expansions, the transition function reaches one, and the parameter estimates lead to relatively higher values of the conditional growth rate. Hence, the closer to one the transition function is, the more likely the economy is to be in expansion. This is why Chart 3 plots the value of one minus the value of the transition function. This chart suggests that periods of low transition function values (high values of one minus the transition function) correspond to the official recessions fairly

13 We do not consider exponential transition functions since they are symmetric around the threshold. These specifications would imply that local dynamics were be the same for expansions and recessions. 
well, which confirms that the regimes may be interpreted as business cycle phases.

Again, the most important conclusion in the STAR specification is that the autoregressive parameter is not significantly different from zero ( $p$-value about 0.08). Thus, our final conclusions should be based on the simpler model STAR2, which excludes the insignificant autoregressive parameter of model STAR1. Finally, we obtain a very high value of the smoothing parameter, which indicates that the transition from one business cycle phase to the other is very quickly. These results can be seen in Figure 6 (Chart 2), where the transition function changes from zero to one almost instantaneously when lagged growth reaches the threshold. This means that the STAR model behaves very similarly to the SETAR model.

\subsection{Markov-Switching autoregressive (MS)}

Probably, this is the most popular and most successful specification for a nonlinear model of GDP growth in the U.S. Initially formulated by Hamilton (1989), it was modified by McConnell and Perez-Quiros (2000) to capture the break in volatility. As in STAR models, the MS specification does not impose the change in regime as sharp. However, in MS models, as opposed to STAR models, shifts are governed by an unobservable state variable that is assumed to follow a Markovian scheme with two regimes and fixed probabilities of transition from one to another.

According to the original specification of Hamilton (1989), output growth may be decomposed into a state-dependent mean, that takes the value $\mu_{1}$ in the first state and $\mu_{0}$ in the second state, and a stationary process $u_{t}$,

$$
y_{t}=\mu_{S_{t}}+u_{t},
$$

where $u_{t}$ follows an $\operatorname{AR}(1) .{ }^{14}$ This specification implies that

$$
y_{t}=\mu_{S_{t}}+\phi_{1}\left(y_{t-1}-\mu_{S_{t-1}}\right)+\varepsilon_{t},
$$

with $\varepsilon_{t} \sim N(0, \sigma)$. Therefore, as in the previous linear and nonlinear specifications, the autocorrelation of output growth may be independently determined by both the shifts in the mean of the process and the autoregressive parameter.

Since the transition between states is assumed to follow a first order Markov chain, probabilities are determined by

$$
P\left(S_{t}=i / S_{t-1}=j, \Omega_{t-1}\right)=P\left(S_{t}=i / S_{t-1}=j\right),
$$

\footnotetext{
14 In the original proposal, James Hamilton (1989) allows for four autoregressive lags. However, lags of any order higher than one are not statistically significant.
} 
where $\Omega_{t}$ represents all the information set in period t. This specification is modified by McConnell and Perez-Quiros (2000) by allowing for two independent Markov processes that capture the two stylized facts, the change in mean (governed by $S_{t}$ ) and the break in volatility (governed by $V_{t}$ ). Therefore, they propose the model

$$
y_{t}=\mu_{S_{t}, V_{t}}+\phi_{1}\left(y_{t-1}-\mu_{S_{t-1}, V_{t-1}}\right)+\varepsilon_{t},
$$

with $\varepsilon_{t} \sim N\left(0, \sigma_{V_{t}}\right)$.

The results of this regression are displayed in Table 4. As shown in the table, Hamilton's original specification, labeled as MS1, implies that the autoregressive parameter is 0.31 and statistically significant (standard error of 0.10). This would imply that, contrary to our previous findings, in the determination of the data generating process, autoregressive parameters matter. However, this result is not robust to including the second stylized fact, the change in volatility. Once we take into account both facts at the same time, as shown in MS2, the autoregressive parameter decays to 0.03 , with a standard error of 0.09 , and is clearly non significant. Thus, confirming our previous results, the serial correlation in logarithmic changes of real GDP seems to be better captured by shifts between states rather than by the autoregressive coefficients.

Figure 7 (Charts 1 and 2) gives a clear intuition of the nature of these results. As Chart 1 shown, the original Hamilton model leads to a statistically significant autoregressive parameter because it does not provide reasonable inferences on the sequence of recessions and expansions identified by the NBER. One potential reason is that the model lacks a mechanism to account for the volatility reduction. In this respect, Chart 2 shows that, once we control for the volatility reduction, the model provides inferences about the business cycles that are in close agreement with the NBER reference cycle, and in this case, autoregressive parameters are not needed in the time series specification.

Given that autoregressive parameters are not statistically significant in the data, we try a new MS specification of a model with no autoregressive parameters. The results are displayed in the third column of Table 4, model MS3, and the probabilities of recession and low variance in Chart 3 of Figure 7. Compared with the probabilities depicted in Chart 2, it is straightforward to conclude that lagged values of output growth do not help at all in forming inference of either the identification of the business cycle phases or in the determination of the timing of the volatility break. In addition, changes in both the log likelihood and the parameter estimates are also negligible. 
Table 4. Markov-switching model of U.S. output growth

\begin{tabular}{|c|c|c|c|}
\hline & MS1 & MS2 & MS3 \\
\hline$\mu_{11}$ & $\begin{array}{c}0.94 \\
(0.09)\end{array}$ & $\begin{array}{c}1.28 \\
(0.14)\end{array}$ & $\begin{array}{c}1.28 \\
(0.13)\end{array}$ \\
\hline$\mu_{21}$ & $\begin{array}{l}-0.93 \\
(0.33)\end{array}$ & $\begin{array}{l}-0.27 \\
(0.24)\end{array}$ & $\begin{array}{l}-0.25 \\
(0.23)\end{array}$ \\
\hline$\mu_{12}$ & & $\begin{array}{c}0.91 \\
(0.06)\end{array}$ & $\begin{array}{c}0.91 \\
(0.06)\end{array}$ \\
\hline$\mu_{22}$ & & $\begin{array}{c}0.22 \\
(0.23)\end{array}$ & $\begin{array}{c}0.24 \\
(0.13)\end{array}$ \\
\hline$\phi_{1}$ & $\begin{array}{c}0.31 \\
(0.10)\end{array}$ & $\begin{array}{c}0.03 \\
(0.09)\end{array}$ & \\
\hline$\sigma_{1}^{2}$ & $\begin{array}{c}0.54 \\
(0.07)\end{array}$ & $\begin{array}{c}0.78 \\
(0.13)\end{array}$ & $\begin{array}{c}0.78 \\
(0.12)\end{array}$ \\
\hline$\sigma_{2}^{2}$ & & $\begin{array}{c}0.16 \\
(0.03)\end{array}$ & $\begin{array}{r}0.16 \\
(0.03)\end{array}$ \\
\hline$p_{11}$ & $\begin{array}{c}0.95 \\
(0.03)\end{array}$ & $\begin{array}{c}0.93 \\
(0.03)\end{array}$ & $\begin{array}{r}0.92 \\
(0.03)\end{array}$ \\
\hline$p_{22}$ & $\begin{array}{c}0.47 \\
(0.21)\end{array}$ & $\begin{array}{c}0.79 \\
(0.08)\end{array}$ & $\begin{array}{c}0.78 \\
(0.08)\end{array}$ \\
\hline$q_{11}$ & & $\begin{array}{c}0.99 \\
(0.01)\end{array}$ & $\begin{array}{c}0.99 \\
(0.01)\end{array}$ \\
\hline$q_{22}$ & & $\begin{array}{c}0.99 \\
(0.01)\end{array}$ & $\begin{array}{c}0.99 \\
(0.01)\end{array}$ \\
\hline $\ln L$ & -72.50 & -48.60 & -49.09 \\
\hline
\end{tabular}

Notes. Entries refer to estimates and standard errors (in parenthesis) that correspond to the Markov-switching model stated as follows:

$y_{t}=\mu_{S_{t}, V_{t}}+\phi_{1}\left(y_{t-1}-\mu_{S_{t-1}, V_{t-1}}\right)+\varepsilon_{t}, \varepsilon_{t} \sim N\left(0, \sigma_{V_{t}}\right)$

Last row refers to the log-likelihoods.

Finally, as in the case of STAR models, the MS approach may also be used to infer the degree of abruptness in the transitions between business cycles. As Chart 3 shows, the filtered probability of low mean dramatically increases around the peaks and decreases around the troughs determined by the NBER 
dating committee. ${ }^{15}$ This is in line with our previous finding that the transitions from expansions to recessions and vice versa are sharp.

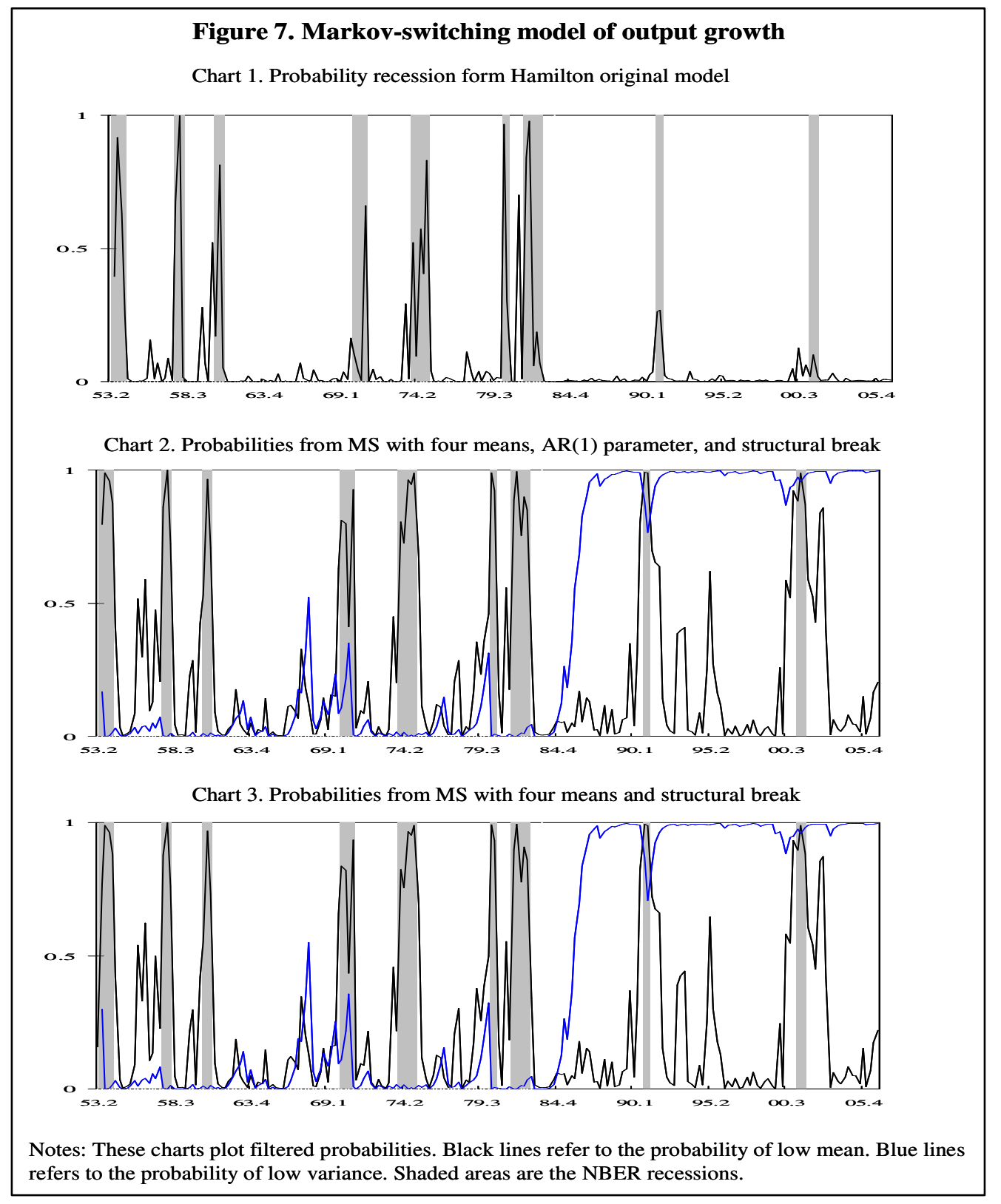

\section{Model evaluation}

\footnotetext{
${ }^{15}$ For example, the probability of low mean rises about $386.33 \%$ and falls about $53 \%$ in the first peak and trough, respectively.
} 
In this section, we compute several tests to show that the models that account for business cycle asymmetries, but omitting autoregressive parameters are dynamically complete. In addition, we evaluate the different estimated models in terms of their forecast errors, by recursively comparing actual with oneperiod-ahead forecasts of output growths. Finally, we examine the extent to which the best of the non-linear models is able to generate cyclical behavior consistent with the actual data.

\subsection{Dynamic completeness}

In this paper we try to show that, once we have accounted for the business cycle pattern in the dynamics of output growth, adding autoregressive parameters is useless. This jump-and-rest effect of business cycles has been detected by using linear models (M4 of Table 2), TAR models (SETAR2 of Table 3), STAR models (STAR2 of Table 3), and MS models (MS3 of Table 4). It is worth checking that all of these specifications are dynamically complete because if we had erroneously eliminated the autoregressive parameters from these models, the unestimated model dynamic would have appeared in the residuals and these would have been serially correlated. On the contrary, if there was nothing to be gained by adding any lag of output growth to models, the residuals of the regression models should be uncorrelated.

The tests that we employ to examine the potential serial correlation in the residuals are presented in Table 5 and they are all based on the null hypothesis of white noise residuals. Box-Pierce, Ljung-Box, and Breusch-Godfrey tests were conducted by using four lags of the corresponding residuals, but the last test also includes one lag of output growth. The $p$-values of these tests are between 0.08 (Ljung-Box for residuals from TAR model) and 0.49 (BreuschGodfrey test for residuals from MS model) so all of them support the view that the models are dynamically complete.

The Brock-Dechert-Scheinkman test has been based on residuals blocks of size 2 whose correlations are checked to lie in hypercubes of size 1.5 times the standard deviation of the residuals. In any case, the tests present $p$-values higher than 0.06, which does not allow us to reject the null hypothesis that residuals are white noises.

Finally, entries of the last row refer to Durbin-Watson test values whose corresponding non autocorrelation zone is about 1.69-2.31. The test statistics are between 1.74 (linear model) and 1.82 (MS model), so they always fall in the non autocorrelation zone. This confirms that the residuals are serially independent. 
Table 5. Autocorrelation of residuals

\begin{tabular}{lcccc} 
& Lineal & TAR & STAR & MS \\
\cline { 2 - 5 } Box-Pierce & 0.11 & 0.09 & 0.09 & 0.41 \\
Ljung-Box & 0.10 & 0.08 & 0.09 & 0.40 \\
Breusch -Godfrey & 0.20 & 0.17 & 0.16 & 0.49 \\
BDS & 0.21 & 0.06 & 0.06 & 0.39 \\
Durbin-Watson & 1.74 & 1.75 & 1.76 & 1.82
\end{tabular}

Notes. Entries that refer to the tests that appear in the first four rows are $p$-values of the null hypotheses that residuals from lineal model (M4 of Table 2), TAR model (SETAR2 of Table 3), STAR model (STAR2 of Table 3), and MS model (MS3 of Table 4) are serially uncorrelated. Box-Pierce, Ljung-Box, and Breusch-Godfrey tests were conducted by using four lags of the corresponding residuals. One lag of the dependent variable is included in the Breusch-Godfrey test. The BDS test is based on residuals blocks of size 2 whose correlations are checked to lie in hypercubes of size 1.5 times the standard deviation of the residuals. Finally, entries of the last row refer to Durbin-Watson test values whose corresponding no autocorrelation zone is about 1.69-2.31.

\subsection{Forecast accuracy}

To evaluate the forecast accuracy of these models we use the Mean Squared Error (MSE), i.e. the average of the squared difference between actual and forecast output growth. ${ }^{16}$ In addition, to compare the forecast accuracy of competing models, we use two different kinds of statistical measures. The first type are usually called tests of equal forecast accuracy. Among them, we consider the Diebold-Mariano (DM), Modified Diebold-Mariano (MDM), Wilcoxon signed-rank (WILC), Morgan-Granger-Newbold (MGN), and Meese-Rogoff (MR) tests, all of them described in Diebold and Mariano (1995) and Harvey, Leybourne, and Newbold (1997). The second type are the forecast encompassing tests (ENC). These tests are based on the fact that, if one model's forecasts encompass the other, then nothing can be gained by combining forecasts. Hence, additional competing forecasts should be statistically insignificant in the regression of actual output growth on the models' forecasts.

Table 6 examines the forecast accuracy of the simple linear AR model, and the nonlinear specifications SETAR, STAR and MS. In addition, we compare our results with the well-know multivariate representation of the dynamics of the main US macroeconomic variables described in King, Plosser, Stock, and Watson (1991, henceforth KPSW). This consists of a vector error correction

\footnotetext{
${ }^{16}$ According to the results showed in Galbraith (2003), we concentrate on one period ahead forecasts.
} 
model of output, consumption and investment with two cointegration relationships. In the in-sample analysis, the MS model exhibits MSE reductions of about one-half, despite the competing model that we consider, and these reductions appear to be statistically significant using the whole set of tests of equal forecast accuracy. In addition, the encompassing tests show that forecasts from the MS model incorporate all the relevant information about output growth in competing forecasts, with the unique exception of the KPSW. Hence, everything points toward the MS model as the best model to fit the insample values of output growth.

Table 6. In-sample and out-of-sample accuracy

\begin{tabular}{|c|c|c|c|c|c|c|c|c|}
\hline & & RMSE & DM & MDM & WILC & MGN & MR & $\overline{E N C}$ \\
\hline \multirow{5}{*}{ IN } & AR & 1.46 & 0.00 & 0.00 & 0.00 & 0.00 & 0.00 & 0.19 \\
\hline & SETAR & 1.99 & 0.00 & 0.00 & 0.00 & 0.00 & 0.00 & 0.28 \\
\hline & STAR & 1.99 & 0.00 & 0.00 & 0.00 & 0.00 & 0.00 & 0.29 \\
\hline & KPSW & 1.62 & 0.00 & 0.00 & 0.00 & 0.00 & 0.00 & 0.00 \\
\hline & MS & 1.00 & --- & --- & --- & --- & --- & --- \\
\hline & AR & 1.59 & 0.05 & 0.06 & 0.00 & 0.00 & 0.01 & 0.06 \\
\hline & SETAR & 1.74 & 0.00 & 0.00 & 0.00 & 0.00 & 0.00 & 0.44 \\
\hline OUT & STAR & 1.74 & 0.01 & 0.01 & 0.00 & 0.00 & 0.00 & 0.70 \\
\hline & KPSW & 1.76 & 0.00 & 0.00 & 0.00 & 0.00 & 0.01 & 0.17 \\
\hline & MS & 1.00 & --- & --- & --- & --- & --- & --- \\
\hline
\end{tabular}

Notes. First column is the relative mean squared error. Other columns refer to the $p$-values of Diebold-Mariano (DM), Modified Diebold-Mariano (MDM), Wilcoxon signed-rank (WILC), Morgan-Granger-Newbold (MGN), Meese-Rogoff (MR) and forecast encompassing tests (ENC). In-sample and out-of-sample refer to 1953.1-2006.4 and 1997.1-2006.4, respectively.

The out-of-sample analysis, on the other hand, is based on recursive onestep-ahead forecasts. That is to say, the sample is successively enlarged with an additional observation and, to construct each of these forecasts, all the parameters are re-estimated. However, prior to developing these forecasts, it may be determined at what time a forecaster would have recognized the volatility slowdown dated in the middle of the eighties. To address this question, Figure 8 uses the approximation suggested by Hansen (1997) to plot the $p$-values of the supremum test defined in Andrews (1993) and the exponential and average tests developed in Andrews and Ploberger (1994) to test the structural break in the volatility of the time series of GDP growth successively enlarged with one additional observation during the period 1997.1-2006.4. This figure reveals that a clear signal of the structural break does not appear until the nineties, so we restrict the out-of-sample analysis to the forecast period 1991.1-2006.4. For this period, the MS model again exhibits the lowest MSE and, with some exceptions, its forecast accuracy seems to be superior to its competitors as suggested by the low $p$-values of forecast accuracy and the large $p$-values of forecast encompassing. 


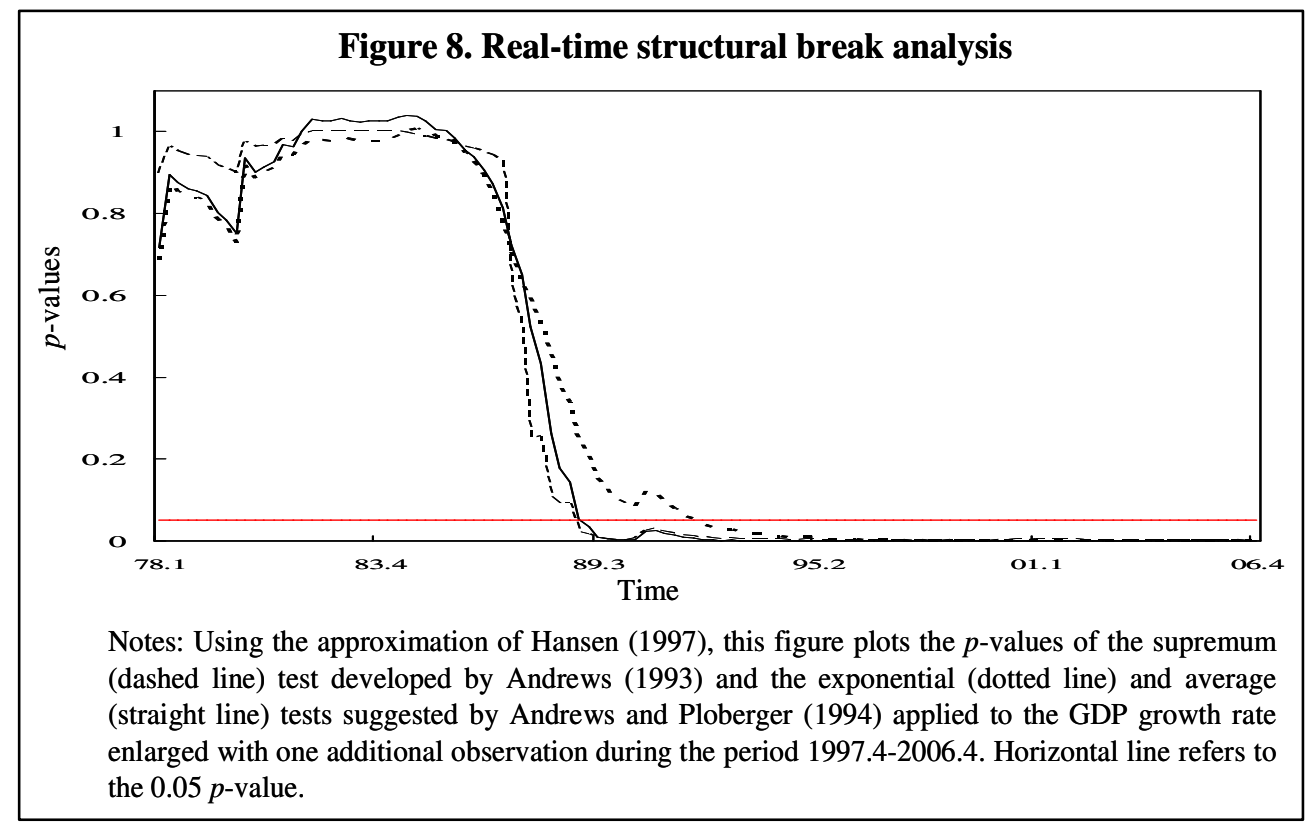

\subsection{Adelman tests}

The previous section suggests that the MS model without autoregressive parameters is a reasonable starting point to forecast GDP growth. However, apart from describing first and second moments reasonably well, to be considered a good representation of the actual data generating process, we should ask whether this class of model is also able to generate cyclical behavior consistent with the data. We perform this exercise by comparing several business cycle characteristics of the data generated by this class of models with those generated by the actual data.

There is an extensive literature on business cycle characteristics which concentrates on the duration, amplitude and shape of the cycle. In this paper, we focus on the aspects of the cycle proposed by Harding and Pagan (2002) and McQueen and Thorley (1993) since they lead to a reasonable representation of the overall form of the typical cycle. In particular, for each of the two phases of the cycle, we consider the duration or average number of periods in the state of the cycle, the amplitude or percentage of gain in an expansion and loss in a recession, the cumulative movements between phases or percentage of wealth accumulated in expansions and lost in recessions, and the excess cumulative movements or difference between actual cumulative movements and the triangle approximation to cumulative movements. ${ }^{17}$ In addition, we report measures of sharpness that compare growth rate changes

\footnotetext{
${ }^{17}$ In the definition of the cumulative movements between the phases of the cycle, wealth is defined as the accumulation of GDP production in each period of time.
} 
two quarters around turning points. ${ }^{18}$ Finally, one additional characteristic that should be generated by the MS process if it seeks to match the observed characteristics of the data is the sample autocorrelation.

The description of these business cycle characteristics must be undertaken first by isolating the turning points in the series. This is specially problematic when we try to report the cyclical behavior of thousands of generated time series. In this paper, we follow the quarterly version of the Bry-Boschan dating procedure suggested by Harding and Pagan (2002) to identify the time series' business cycle turning points. ${ }^{19}$

The first two columns of Table 7 provide an overview of the business cycle characteristics concerning the actual data of US output growth. Expansions are about six times longer than recessions. The amplitude of expansions is also much larger than in recessions, basically because the latter are short-lived. It may also be induced from this that, in expansions, the accumulated gains are much higher than the accumulated losses of recessions. The measures of excess show that contractions are similar and expansions are different from the triangle approximation of the accumulated loses and gains, respectively. The sign of the excess in expansion is consistent with the rapid recovery in the early part of the expansion that has been documented in the literature. Finally, according to the results of McQueen and Thorley (1993), the sharpness of troughs is roughly twice the sharpness of peaks, which supports the view that peaks are relatively more rounded than troughs.

Let us now examine the ability of the MS model to match the characteristics found in the data. To do this, we collect the estimates of the model MS3 displayed in the third column of Table 4. Then we generate 10,000 Montecarlo time series simulations using these estimates, and identify their turning points. Finally, we compute the set of business cycle characteristics generated by each of these simulations. The last two columns of Table 7 provide some summary statistics for the business cycle characteristics generated by the MS model: the mean and the percentile of the Montecarlo distribution in which the actual business cycle statistic is placed. Because the actual business cycle statistics are not in the extreme tails of the Montecarlo distributions, the MS model does a reasonable job of producing recessions and expansions with business cycle characteristics consistent with those of the actual data. For the purposes of this paper, the ability of the MS model to generate time series with similar average correlation to that observed in the data is of notable interest, specially if we recall that the process that generates the simulations does not include any autoregressive parameter. This confirms the empirical reliability of the jumpand-rest effect of business cycles and the ability of the Markov switching representation to generate time series with business cycle characteristics similar to those of the observed data.

\footnotetext{
${ }^{18}$ For a comprehensive overview of these measures, we refer the reader to the original papers.

19 This algorithm isolates the local minima and maxima in a series, subject to reasonable constraints on both the length and amplitude of expansions and contractions.
} 
Table 7. Summary statistics for actual data and Markov-switching simulations

\begin{tabular}{|c|c|c|c|c|}
\hline & \multicolumn{2}{|c|}{ Actual } & \multicolumn{2}{|c|}{ Simulations } \\
\hline & Expansions & Recessions & Expansions & Recessions \\
\hline Duration & 20.3 & 3.4 & $\begin{array}{c}15.0 \\
{[0.64]}\end{array}$ & $\begin{array}{c}3.0 \\
{[0.54]}\end{array}$ \\
\hline Amplitude (\%) & 20.5 & -1.7 & $\begin{array}{c}12.4 \\
{[0.60]}\end{array}$ & $\begin{array}{c}-4.8 \\
{[0.62]}\end{array}$ \\
\hline \multirow[t]{2}{*}{ Excess (\%) } & 1.3 & -0.2 & 1.1 & 0.2 \\
\hline & & & {$[0.86]$} & {$[0.20]$} \\
\hline \multirow[t]{2}{*}{ Cumulation (\%) } & 311 & -4.8 & $\begin{array}{c}115 \\
{[0.68]}\end{array}$ & $\begin{array}{c}-3.0 \\
{[0.47]}\end{array}$ \\
\hline & Peaks & Troughs & Peaks & Troughs \\
\hline Sharpness & 0.021 & 0.039 & $\begin{array}{l}0.030 \\
{[0.06]}\end{array}$ & $\begin{array}{c}0.031 \\
{[0.90]}\end{array}$ \\
\hline Autocorrelation & & & & \\
\hline
\end{tabular}

Notes. Definitions for these business cycle characteristics are in the text. The percentile in the simulations that the actual business cycle characteristic occupies is in square brackets.

\section{Conclusion}

In this paper, we have found empirical evidence in favor of what we call the jump-and-rest effect of business cycles: Once we take into account business cycle recession and expansion sequences similar to that provided by the NBER, and the break in volatility in the mid-eighties, further lags of output growth do not matter when explaining the dynamics of the U.S. output growth rate. We have shown that this result is robust to the sample period, to many other alternative sequences of business cycle dates, to other macroeconomic aggregates such as consumption, investment, and sales, and to several alternative nonlinear specifications determining endogenously the timing of the turning points. We believe that this result can be considered as "a new stylized fact of the U.S. economy".

It is important to realize that the jump-and-rest effect of business cycles does not imply that the rest effect negates the presence of cycles in any way. In fact, the serial correlation that characterizes the regime switches is "substituting" for the serial correlation that we would normally model via a first order lag structure. Note that the NBER indicator used in the linear approximation is serially correlated, as is the threshold indicator in the TAR 
model, the transition function in the STAR model, and the state variable in the Markov model. The switch variables are, then, accounting for cycles that were previously accounted for by autocorrelation coefficients.

The consequences of this new fact for future empirical and theoretical macroeconomic analysis are diverse and depend on the interest of the reader. From an empirical point of view, these simple dynamics facilitate the understanding and development of forecasts, they reduce to a minimum the complexity of impulse response functions and dynamic multipliers, specially those developed in nonlinear contexts, and they simplify the simulation and calibration analysis by overcoming unsolved computational problems. From a theoretical point of view, these findings provide empirical support to those theoretical models that describe the data generating process of output growth jumping between two equilibria of high and low growth. In addition, the jumpand-rest dynamics add further for investigating the empirical reliability of theoretical simulations. Finally, these dynamics may act as a guideline for resuscitating theoretical models that were neglected when autoregressive parameters were accepted as the source of the positive autocorrelation of output growth.

\section{References}

[1] Andrews, D. (1993): "Test for parameter instability and structural change with unknown change point," Econometrica, 61, 821-856.

[2] Andrews, D., and W. Ploberger (1994): "Optimal tests when a nuisance parameter is present only under the alternative," Econometrica, 62, 13831414.

[3] Azariadis, C., and B. Smith (1998): "Financial intermediation and regime switching in business cycles," American Economic Review, 85, 516-536.

[4] Camacho, M. (2004): "Vector smooth transition regression models for US GDP and the composite index of leading indicators," Journal of Forecasting, 23, 173-179.

[5] Campbell, J., and G. Mankiw (1987): "Are output fluctuations transitory?" Quarterly Journal of Economics, 102, 857-880.

[6] Cochrane, J. (1988): "How big is the random walk in GNP?" Journal of Political Economy, 96, 893-920.

[7] Cogley, T., and J. Nason (1995): "Output dynamics in real-business-cycle models," American Economic Review, 85, 492-511.

[8] Diebold, F., and R. Mariano (1995): "Comparing predictive accuracy," Journal of Business and Economic Statistics, 13, 253-263.

[9] Evans, G., S. Honkapohja, and P. Romer (1998): "Growth cycles," American Economic Review, 88, 495-515.

[10] Galbraith, J.W (2003): "Content horizons for univariate time-series forecast," International Journal of Forecasting, 19, 43-55. 
[11] Hamilton, J. (1989): "A new approach to the economic analysis of nonstationary time series and the business cycles," Econometrica, 57, 357384.

[12] Hansen, B. (1999): “Testing for linearity," Journal of Economic Surveys 13, 551-576.

[13] Harding, D., and A. Pagan (2002): "Dissecting the cycle: A methodological investigation," Journal of Monetary Economics, 40, 365-381.

[14] Harvey, D., S. Leybourne, and P. Newbold (1997): "Testing the equality of prediction mean squared errors," International Journal of Forecasting, 13, 281-291.

[15] Kim, Ch., and Ch. Nelson (1999): "Has the U.S. economy become more stable? A Bayesian approach based on a Markov-switching model of the business cycle," The Review of Economics and Statistics, 81, 608-616.

[16] Kim, Ch., J. Morley, and J. Piger (2005): "Nonlinearity and the permanent effects of recessions," Journal of Applied Econometrics, 20, 291309.

[17] Morley, J., and J. Piger (2006): "The importance of nonlinearity in reproducing business cycle features," in C. Milas, P. Rothman, and D. van Dijk, eds., Nonlinear Time Series Analysis of Business Cycles, Amsterdam: Elsevier Science, 75-93.

[18] King, R., Ch. Plosser, J. Stock, and M. Watson (1991): "Stochastic trends and economic fluctuations," American Economic Review, 81, 819-840.

[19] McConnell, M., and G. Perez-Quiros (2000): "Output fluctuations in the United States: What has changed since the early 80s?" American Economic Review, 90, 1464-1476.

[20] McQueen, G., and S. Thorley (1993): "Asymmetric business cycle turning points," Journal of Monetary Economics, 31, 341-362.

[21] Nelson, Ch., and Ch. Plosser (1982): "Trends and random walks in macroeconomic time series," Journal of Monetary Economics, 10, 139-162.

[22] Potter, S. (1995): “A nonlinear approach to US GNP," Journal of Applied Econometrics, 10, 109-25.

[23] Teräsvirta, T. (1994): "Specification, estimation, and evaluation of smooth transition autoregressive models," Journal of the American Statistical Association, 89, 208-218.

[24] Teräsvirta T. (1995): "Modelling nonlinearity in U.S. Gross national product 1889-1987," Empirical Economics, 20, 577-97.

[25] Tong, H. (1978): "On a threshold model," in C.H. Chen, ed., Pattern Recognition and Signal Processing, Amsterdam: Sijhoff and Noordhoff.

[26] Watson, M. (1986): "Univariate detrending methods with stochastic trends," Journal of Monetary Economics, 18, 49-75. 